\title{
Comparative Study of Prestress Losses
}

\author{
Mustapha Boukendakdji \\ College of Engineering \\ Department of Civil Engineering \\ University of Hail \\ Hail, Saudi Arabia \\ m.boukendakdji@uoh.edu.sa
}

\author{
Mabrouk Touahmia \\ College of Engineering \\ Department of Civil Engineering \\ University of Hail \\ Hail, Saudi Arabia \\ m.touahmia@uoh.edu.sa
}

\author{
Belkacem Achour \\ College of Engineering \\ Department of Civil Engineering \\ University of Hail \\ Hail, Saudi Arabia \\ b.achour@uoh.edu.sa
}

\begin{abstract}
This paper compares the prestress losses as calculated by four different design codes; British standard CP110, Comite Europeen du Beton 70 and 78, American Concrete Institute 77 and the Prestressed Concrete Institute method (PCI). The comparison is done by determining the total losses which take place in a rectangular prestressed concrete beam for both pretensioning and post-tensioning systems. The results show that total losses calculated for the post-tensioning method are higher than those calculated for the pre-tensioning method, which is not the usual case. It seems that the PCI method may be required for special structures or for simply supported slender members which may be sensitive to small changes in deflections. However, for non-special structures, or where actual losses have little effect on the design, it is better to compute losses by the ACI method because it is simple and does take into considerations interactions between the various sources of losses. However, it is not possible to conclude which method gives the more accurate prediction of shrinkage and creep without direct co-relation to realistic insitu data.
\end{abstract}

Keywords-losses; prestress; pre-tension; post-tension; creep; shrinkage; relaxation

\section{INTRODUCTION}

Prestressed concrete is a particular form of reinforced concrete. Prestressing involves the application of an initial compressive load to the structure to reduce or eliminate the internal tensile force and, thereby, control or eliminate cracking [1]. It has long been recognized that the prestress introduced into concrete, does not remain constant but decreases gradually with the progress of time. It is therefore necessary for the designer to estimate the losses of prestress throughout the anticipated life of the structure and to provide an initial prestress which is sufficiently high so that the structural integrity will not be impaired as the losses take place. In a pretensioned member, the major components of prestress losses are those due to elastic, creep and shrinkage deformation of concrete and that due to relaxation of steel. In a post-tensioned member, additional losses due to friction take place. Relaxation is theoretically defined as the decrease of stress in the prestressing element when it is restrained to a constant length. In the pre-tensioning process, part of the loss due to relaxation occurs before transfer. Shrinkage is the shortening of the concrete due to loss of water which results in loss of the prestressing stress. After an initial high rate of drying shrinkage, concrete continues to shrink for a long period of time but at a continuously decreasing rate. In general drying shrinkage is directly proportional to the water-cement ratio and inversely proportional to the aggregate-cement ratio. For a given water-cement ratio shrinkage increases with increasing cement content [2]. Creep is the time dependent deformation of concrete due to sustained compressive stresses in the fibres. One of the difficulties in determining these losses accurately is the assumption that the stress remains constant. This is not true because there is gradual reduction in stress during the life of the structure. Creep of concrete is influence by many factors, such as: aggregate and cement content and water-cement ratio [3-4].

Many method and design recommendations have been developed to predict prestress losses. A notably one is the time step method. The basis of this method is to divide the service life into small time intervals during which the stress relaxation, creep strain and shrinkage strain can be assumed to be independent of each other. In each small time interval prestress loss due to stress relaxation and strain changes due to creep and shrinkage are calculated. The stress levels at the end of each time interval are used in the next succession time interval. This procedure is continued until the required service life of the structure is reached. The ACI-209R-82 model [5], the CEB-FIP model code 1990 [6] and the B3 model [7] are recent and are based on extensive research as well as experimental studies. The measured creep and shrinkage strains were compared with different code predictions. In [8], authors observed that CEBFIP model code [6], slightly over predicts at an early age but matches well at a later age. An error in computing losses can affect service conditions such as camber, deflection and cracking. The underestimation of losses might result in cracking.

The main purpose of this research is a comparative study of the loss of prestress to four different design codes; British standsrd CP110 [9], Comite Europeen du Beton 70 [10] and 78 [11], and American Concrete Institute 77 [12]. The latter recommends PCI [13] and ACI [12] methods for calculating prestress losses. The comparison is done by determining the total losses which take place in a rectangular prestressed concrete beam for both pre-tensioning and post-tensioning systems. 


\section{COMPARATIVE STUDY OF LOSSES}

The comparison is performed by determining the total losses which take place in a rectangular prestressed concrete beam for both pre-tensioning and post-tensioning systems. CEB 70 [10] and CEB 78 [11] are supposed to predict shrinkage and creep more accurately than ACI [12] and CP110 [9] methods because they use some graphs to take into account some factors such as relative humidity, temperature of curing, time of loading and theoretical thickness.

\section{A. Beam Data}

The beam is of rectangular cross section $200 \mathrm{~mm}$ wide by $380 \mathrm{~mm}$ deep. It contains 6 wires (diameter $=7 \mathrm{~mm}$ ) $40 \mathrm{~mm}$ from the soffit, six wires $75 \mathrm{~mm}$ from the soffit and three wires $25 \mathrm{~mm}$ from the top. Each wire is tensioned by a force of $\mathrm{Fi}=47 \mathrm{kN}$ before transfer which corresponds to a total force of $F=705 \mathrm{kN}$. The following apply:

- $E_{s}=$ modulus of elasticity of steel=200 GPa

- $E_{c i}=$ modulus of elasticity of concrete at transfer=31 GPa.

- $E_{c}=$ modulus of elasticity of concrete at 28 days $=35 \mathrm{GPa}$.

- $F_{c u}=$ characteristic concrete cube strength $=50 \mathrm{MPa}$

- $F_{c i}=$ concrete strength at transfer $=40 \mathrm{MPa}$.

- $F_{c}^{\prime}=$ compressive strength of concrete at 28 days (cylindrical specimens) $=40 \mathrm{MPa}$.

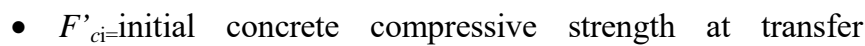
(cylindrical specimens) $=32 \mathrm{MPa}$.

- $A_{p}=$ area of presetressing tendons $=577.2 \mathrm{~mm}^{2}$.

- $F_{p i}=$ prestressing stress at the jacking end=1221 MPa.

- A area of concrete $=79145 \mathrm{~mm}^{2}$

- $Y_{b}=$ distance of lowest point from centroid of concrete section $=187 \mathrm{~mm}$.

- $I=$ area second moment of concrete section $=9.759 \times 10^{8}$ $\mathrm{mm}^{4}$.

- $Z_{b}=$ section modulus for lowest point in concrete section $=13.941 \times 10^{6} \mathrm{~mm}^{3}$.

- $Z_{t}=$ section modulus for highest lowest point in concrete section $=5.056 \times 10^{6} \mathrm{~mm}^{3}$.

- $Z_{c}=$ section modulus for the tendons level $=13941 \times 106 \mathrm{~mm}^{3}$.

- $E=$ eccentricity of prestressing force with respect to centroid of concrete section. $=70 \mathrm{~mm}$

- $M_{d l}=$ dead load moment at midspan=12.825 kN.m.

- $F_{p u}=$ characteristic strength of prestressing steel=1750 MPa.

- $F_{p i} / f_{p u}=0.7$

- Age of loading (transfer) $=13$ days.
Losses due to friction in the duct are calculated from the following expression:

$$
\Delta F_{f}=F \times\left[1-e^{(-k x)}\right]
$$

where $x=3.75 \mathrm{~m}$ (distance from the end of the beam to midspan) and $k=0.0033$ (constant depending on the type of duct).

The loss of prestress computed by CEB 78 method (Comite Europeen du Beton) [11] is the sum of the losses which occur before the concrete has been prestressed, the instantaneous losses, and the losses due to time dependent deformations. The evaluation of the time dependent losses due to shrinkage and creep of the concrete and relaxation of the steel must take account of the interdependence of these phenomena as follows:

$$
\Delta \sigma_{p \infty}=\Delta \sigma_{p, c+s, \infty}+\Delta \sigma_{p, r e l, \infty}\left[1-2 \frac{\Delta \sigma_{p, c+s, \infty}}{\sigma_{p o}}\right]
$$

In which $\Delta \sigma_{p, c+s, \infty}$ denotes the loss of prestress in steel due toa shortening of the concrete as a result of creep and shrinkage.

The ACI (American Concrete Institute) method was developed to estimate the losses from time dependent effects without having to break the life history of the beam into several time intervals. The interactions between the various sources of losses have been considered in setting the various coefficients which are used, thus it is significantly better than summing up individual estimates for loss of steel stress from elastic shortening, creep, and shrinkage of concrete together with relaxation of the steel. Loss of prestress due to creep is computed for bonded members from the following expression:

$$
C R=K_{c r} \times\left(\frac{E_{s}}{E_{c}}\right) \times\left(f_{c i r}-f_{c d s}\right)
$$

in which $k_{c r}=2.0$ for pre-tensioned members and $K_{c r}=1.6$ for post-tensioned members. Loss of prestress due to shrinkage is given by:

$$
S H=550 \times 10^{-6} \times K_{s h} \times E_{S} \times\left(1-0.06 \frac{V}{S}\right) \times(1.5-0.015 R H)
$$

where V/S : Volume to surface ratio, $R H$ : Average relative humidity surrounding the concrete member, $K_{s h}: 1.0$ for pretensioned members

\section{RESULTS AND DISCUSSION}

The losses of prestress for the beam in the pre-tensioning and post-tensioning processes are given in Tables I and II respectively. It is assumed that half of relaxation occurs before transfer. Total losses calculated for the post-tensioning method are higher than those calculated for the pre-tensioning method (Figure 1), which is not the usual case. This is due to the fact that prestress losses caused by anchorage set are very high. The effect of anchorage set losses is more pronounced with short tendons (i.e. beam $\operatorname{span}=7.5 \mathrm{~m}$ ). This loss can be overcomed by overstressing each wire or (but not greater than 
$80 \%$ ultimate tensile strength) or re-stressing and placing shims behind each anchor. Usually losses determined for the post-tensioning method are smaller than those determined for the pre-tensioning method because:

- Losses due to elastic shortening, in the case of posttensioning, are less than half than those for pre-tensioning.

- There is no loss due to relaxation before transfer.

- The effect of shrinkage of concrete before transfer is not taken into account in the case of post-tensioning.

However, losses after transfer calculated for the posttensioning method are lower than those calculated for the pretensioning method (Figure 2).

TABLE I. PRESTRESS LOSSES IN THE PRE-TENSIONING PROCESS FOR CP110, CEB 70,78 AND ACI METHODS IN MPa

\begin{tabular}{|c|c|c|c|c|}
\hline LOSSES DUE TO & CP110 & CEB70 & CEB 78 & ACI \\
\hline Half relaxation & 15.25 & 15.26 & 15.26 & 15.26 \\
\hline Elastic deformation & 73.35 & 73.35 & 73.35 & 63.68 \\
\hline At transfer & 88.60 & 88.60 & 88.60 & 78.94 \\
\hline Half relaxation & 14.1 & 31.7 & 39 & 17.87 \\
\hline Shrinkage & 60.0 & 44.0 & 52.4 & 41.6 \\
\hline Creep & 106.1 & 155.2 & 186.6 & 114.00 \\
\hline After transfer & 180.2 & 229.7 & 278 & 173.47 \\
\hline Total losses & 268.8 & 318.3 & 366.6 & 252.42 \\
\hline \% of losses & $22.0 \%$ & $26.07 \%$ & $30.0 \%$ & $20.65 \%$ \\
\hline
\end{tabular}

TABLE II. PRESTRESS LOSSES IN THE POST-TENSIONING PROCESS FOR CP110, CEB 70,78 AND ACI METHODS IN MPa

\begin{tabular}{|c|c|c|c|c|}
\hline LossES DUE TO & CP110 & CEB70 & CEB78 & ACI \\
\hline Friction & 15.60 & 15.60 & 15.60 & 14.85 \\
\hline Anchorage set & 131.60 & 131.6 & 131.60 & 131.60 \\
\hline Elastic deformation & 32.30 & 27.80 & 32.32 & 31.0 \\
\hline At transfer & 179.5 & 175.0 & 179.51 & 177.45 \\
\hline Relaxation & 26.04 & 29.2 & 36.3 & 9.77 \\
\hline Shrinkage & 40.0 & 44.0 & 47.8 & 32.66 \\
\hline Creep & 69.76 & 142.4 & 170.4 & 86.06 \\
\hline After transfer & 135.80 & 215.6 & 254.5 & 128.49 \\
\hline Total losses & 315.30 & 390.6 & 434.0 & 305.94 \\
\hline \% of losses & $25.8 \%$ & $32.0 \%$ & $35.5 \%$ & $25.34 \%$ \\
\hline
\end{tabular}

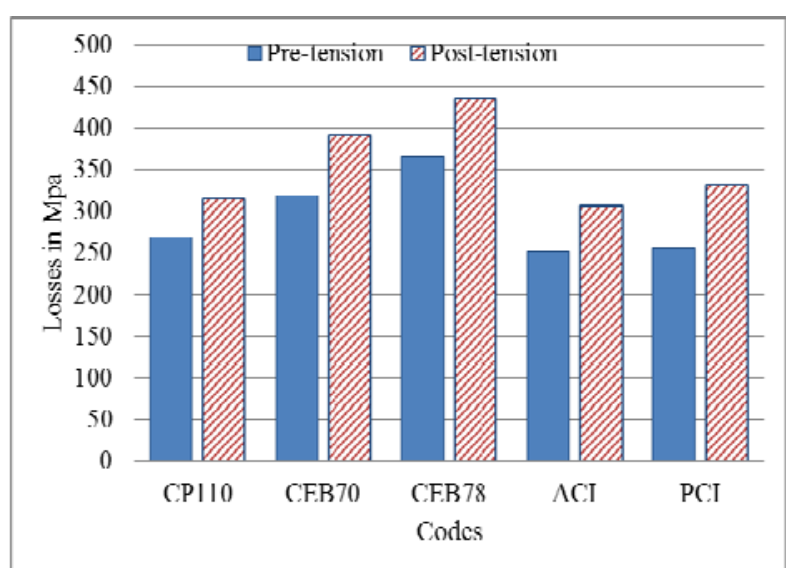

Fig. 1. Comparison of Total Losses between Pre-tension and Post-tension.

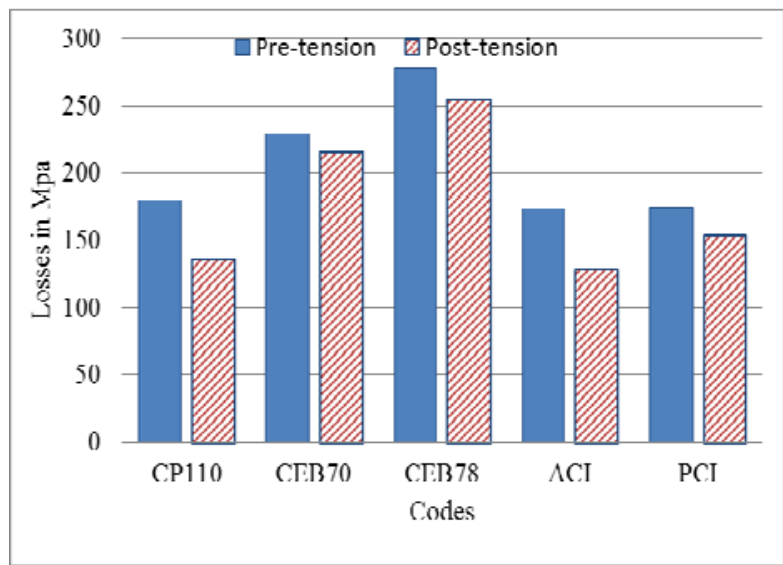

Fig. 2. Comparison of Losses after Transfer between Pre-tension and Post-tension.

This is due to the fact that the effect of shrinkage of concrete before transfer is not taken into account in the case of post-tensioning. The shrinkage in the case of post-tensing method is less than those of pre-tensioning method as shown in Figures 3 and 4.

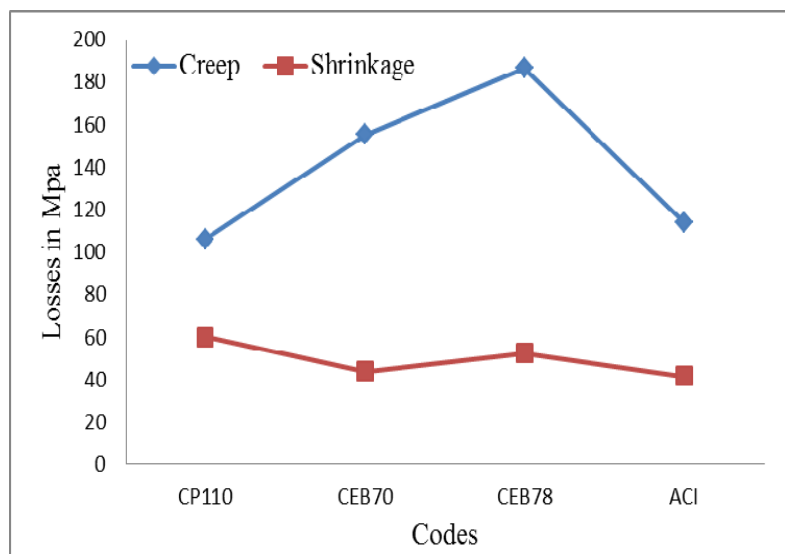

Fig. 3. Losses due to creep and shrinkage in the case of pre-tension for different codes.

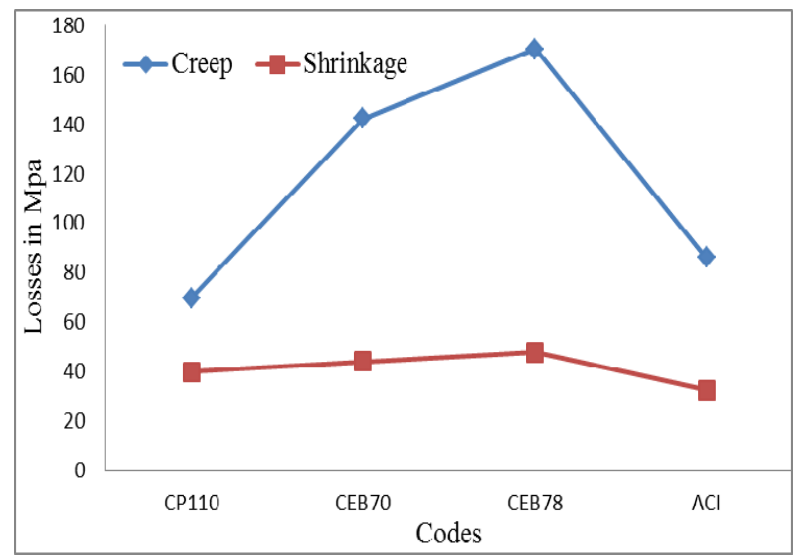

Fig. 4. Losses due to creep and shrinkage in the case of post-tension for different codes. 
In $\mathrm{CP} 110$, the value of shrinkage in post-tensioning is approximately two thirds of those given in pre-tensioning (Table III). Losses calculated by CP110 are smaller than those calculated by CEB 70 or and this is due to the fact that ultimate shrinkage and creep strains given by CP110 are smaller than those predicted by both other methods (Table III).

TABLE III. PREDICTED SHRINKAGE BY DIFFERENT CODES

\begin{tabular}{|c|c|c|}
\hline \multirow{2}{*}{ CODES } & \multicolumn{2}{|c|}{ Shrinkage in micro strain per unit length } \\
\cline { 2 - 3 } & Pre-stression & Post-tension \\
\hline CP 110 & 300 & 200 \\
\hline CEB 70 & 220 & 220 \\
\hline CEB 78 & 262 & 239 \\
\hline
\end{tabular}

It seems that $\mathrm{CP} 110$ underestimates shrinkage and creep for thin sections (theoretical thickness $130 \mathrm{~mm}$ ) because CP110 gives only one value of shrinkage for all concrete members even though it is known that shrinkage varies with the size of the member. Thus if another example were done with a larger member, CP110 may give higher losses than those given by CEB70nor CEB78 method because both methods take into account size of the member. The higher value of predicted shrinkage and creep strains by CEB 78 causes the losses of prestress to be higher than those of CEB 70. For example in pre-tensioning process; CEB 70 predicts a shrinkage strain of 220 microstrain and a creep strain of 776 microstrain per unit length, and CEB 78 predicts 262 and 933 microstrain for shrinkage and creep strain respectively (Figure 5).

It is not possible to conclude which method of these two gives the more accurate prediction without direct co-relation to realistic in-situ data, but according to [14], the CEB 70 methods yields a slightly greater accuracy than that of the CE78. So it is preferable to use the CEB 70method for predicting creep and shrinkage. A general comment is that the CEB78 method makes no use of composition factors such as cement content and water cement ratio. Also the effect of age at loading upon drying creep is not represented.

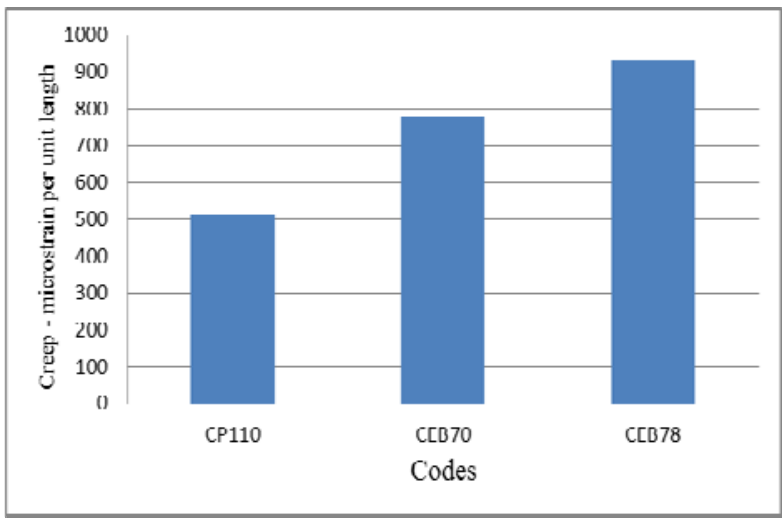

Fig. 5. Creep in Microstrain per unit length for different codes.

Since prestress losses due to steel relaxation and creep and shrinkage of concrete are inter-dependent and are time dependent, the PCI method (or step-by-step procedure) can be used in order to account for changes which occur in successive time intervals. It is recommended that a minimum of four time intervals be used. The losses of prestress calculated by the PCI method in the pre-tensioning and post-tensioning processes are given in Tables IV and $\mathrm{V}$ respectively. The losses calculated by the PCI method are lower than CEB 70 and 78 methods in both the pre-tensiong and post-tensioning process (Figures 1 and 2).

TABLE IV. LOSSES OF PRESTRESS IN THE PRET-TENSIONING PROCESS FOR PCI METHODS IN MPa

\begin{tabular}{|c|c|c|}
\hline STAGES & PERIODS & LOSSES (MPA) \\
\hline 1 & Tensioning steel to transfer (0-13 days) & 81.27 \\
\hline 2 & 13- 30 days & 57.36 \\
\hline 3 & 30 days to One year & 81.53 \\
\hline 4 & One year to 40 years & 35.40 \\
\hline \multicolumn{2}{|c|}{ Total losses } & 255.56 \\
\hline & $\%$ of losses & $21.10 \%$ \\
\hline
\end{tabular}

TABLE V. LOSSES OF PRESTRESS IN THE POST-TENSIONING PROCESS FOR PCI METHODS IN MPa

\begin{tabular}{|c|c|c|}
\hline STAGES & PERIODS & LOSSES (MPA) \\
\hline 0 & $\begin{array}{c}\text { Elastic shortening + Friction }+ \\
\text { Anchorage set }\end{array}$ & 177.52 \\
\hline 1 & $13-30$ days & 55.92 \\
\hline 2 & 30 days to One year & 65.12 \\
\hline 3 & One year to 40 years & 32.07 \\
\hline \multicolumn{2}{|c|}{ Total losses } & 330.63 \\
\hline & $\%$ of losses & $27.38 \%$ \\
\hline
\end{tabular}

\section{CONCLUSION}

Although the ACI method is a very simple method for predicting losses without having to break the life history of the beam into several time intervals and taking into account the various sources of losses gives nearly the same amount of losses as given by the PCI method (step by step method) which is considered as a lengthy method. The ACI method gives a constant value of creep which is independently of relative of humidity or volume to surface ratio. It seems that this method underestimates creep for high volume to surface ratio and high relative humidity. Determination of prestress loss in accordance with the PCI method (step by step method) is a lengthy and laborious procedure because the rate of loss due to one factor, such as relaxation of tendons, is continually altered by changes in stress due to other factors such as shrinkage and creep of concrete. Rate of creep is, in turn, altered by the change in tendon stress. Many of these factors are further dependent upon such uncertainties as material properties, time of loading, method of curing of concrete, environmental conditions and construction details. Therefore, This method may be required for special structures or for simply supported slender members which may be sensitive to small changes in deflections. For non-special structures, or where actual losses, greater or smaller than the estimated, have little effect on the design, it is better to compute losses by ACI method because it is simple and does take into considerations interactions between the various sources of losses, than simply summing up individual estimates of losses. 


\section{ACKNOWLEDGMENT}

The research reported herein was funded by the Deanship of Scientific Research at the University of Hail, Saudi Arabia, under the contract (0150209). The author would like to extend his gratitude to the Deanship of Scientific Research and to the College of Engineering at the University of Hail for providing all facilitations required for this research.

\section{REFERENCES}

[1] R. I. Gilbert, N. C. Mickleborough, G. Ranzi, Design of prestressed concrete to AS 3600-2009, CRC Press, 2016

[2] J. J. Brooks, "30-year creep and shrinkage of oncrete", Magazine of Concrete Research, Vol. 57, No. 9, pp. 545-556, 2005

[3] A. M. Neville, W. H. Dilger, J. J. Brooks, "Creep of plain and structural concrete", Construction Press, London, pp. 361, 1984

[4] J. J. Brooks, P. J. Wainwright, M. boukendakdji, "Influences of slag type and replacement level on strength, elasticity, shrinkage and creep of concrete", $4^{\text {th }}$ Inter. Conf. on the use of Fly Ash, Silica Fume, Slag and Natural Pozzolans in Concrete, Vol 2, Istanbul, Turkey, ACI Spec. Publ., pp 1325-1341, 1992

[5] ACI Committee 209, "Guide for modeling and calculating shrinkage and creep in hardened concrete", ACI Report 209.2R-08, Farmington Hills, 2008

[6] CEB-FIP Model Code "Model code for concrete structures", Thomas Telford Services Ltd., London, Great Britain; also published by Comité euro-international du béton (CEB), Bulletins d'Information No. 213 and 214, Lausanne, Switzerland, 1990

[7] Z. P. Bazant, Q. Yu, "Excessive long-time deflections of prestressed box girders", ASCE J. of Structural Eng., Vol. 138, No. 6, pp. 676-696, 2012

[8] K. Jayakumar, A. Upadhyay, N. M. N. Bhandari, "Artificial neural network for predicting creep and shrinkage of concrete", Journal of Advanced Concrete Technology, Vol. 6, No. 1, pp.135-142, 2008

[9] CP110, The Structural Use of Concrete- Part 1, Britsih Standard Code of Practice, 1972

[10] CEB-FIP, International recommendations for the design and construction of concrete structures principles recommendations, European Concrete Committee, 1970

[11] CEB-FIP, Model code for concrete structures, Comitee European du Beton, Fedeation Internationale de la Precontraite, Paris, 1978

[12] ACI Committee 318, Building code requirements for reinforced concrete (ACI 318-77), American Concret Institute, Detroit, 1977

[13] PCI Committee on Prestress Losses, "Recommendations for estimating prestress losses", Prestressed Concrete Institute Journal, Vol. 20, No. 4 pp. $43-75,1975$

[14] F. M. Abdellatif, Long-term prediction of deformation of plain concrete, MSc Thesis, Department of Civil Engineering, Leeds University, 1982 